\title{
Outorga de lançamento de efluentes em rios - estimativas de vazões de diluição
}

\section{Permits for wastewater discharge into rivers - estimation of required water flow for dilution}

\section{Lorenza Uliana Zandonadi ${ }^{1}$, Antonio Sérgio Ferreira Mendonça ${ }^{2}$ e José Antonio Tosta dos Reis ${ }^{3}$}

\author{
${ }^{1}$ Engenheira Ambiental, Mestrado em Engenharia Ambiental. \\ Agência Reguladora de Saneamento e Infraestrutura Viária do Espírito Santo. \\ lorenzazan@yahoo.com.br.
}
${ }^{2}$ Engenheiro Civil, Mestrado em Engenharia Civil, Doutorado em Engenharia de Recursos Hídricos.
Departamento de Engenharia Ambiental, Universidade Federal do Espírito Santo. anserfm@terra.com.br.
${ }^{3}$ Engenheiro Civil, Mestrado em Engenharia Ambiental, Doutorado em Engenharia Civil.
Departamento de Engenharia Ambiental, Universidade Federal do Espírito Santo tosta@ct.ufes.br.

Recebido: 07/02/14 - Revisado: 10/02/14 - Aceito: 09/07/14

\begin{abstract}
RESUMO
A outorga para lançamento de efluentes representa importante instrumento para controle da poluição de águas no Brasil. Entretanto, no País, não existe uniformidade de critérios para análise de solicitaçoes de outorga. Existem, na literatura, diversas propostas de metodologias para estimativas de vazões de diluição de efluentes a serem consideradas em processos de outorga. Neste sentido, o presente trabalhoanalisoudiversas propostas disponiveis, com o objetivo de compararvalores de vazões de diluição estimadas através de cada metodologia. Foram realizadas simulaçoes para cinco cenários, que incluem presença de lançamentos e captações. Foram utilizadas metodologias propostas por Kelman (1997), Hora (2001), Cardoso da Silva e Monteiro (2004), Nahon (2006), Roques (2006), além da Equação de Balanço de Massa, modificada por MMA (2000). Os resultados mostraram que as diferentes metodologias podem resultar em valores muito diversos de vazões de diluição, em função das diferentes variáveis consideradas nas equações e dos valores adotados para estas variáveis. A não consideração do processo de autodepuração usualmente resulta em superestimação de valores de vaz̃ões de diluição a jusante dos pontos de lançamento previstos. A incorporação das condições de qualidade no corpo d'água à montante dos lançamentos, por sua vez, faz. com que a outorga fique condicionada aos outros lançamentos já existentes anteriormente no rio, outorgados ou não. Neste contexto, avaliações de solicitaçoes de outorga que considerem a real qualidade do curso d'água tornam oprocesso de análise mais próximos da realidade embora exijam maiores esforcos de monitoramento dos corpos d'água.
\end{abstract}

Palavras Chave: Recursos hídricos. Qualidade da água. Outorga. Vazão de diluição.

\begin{abstract}
The analysis of permits for wastewater discharge is an important instrument for controlling water pollution in Brazil. Brazilian states adopt different criteria for the analysis of requests for permits. Several methods were developed for estimating river water discharges necessary for effluent dilution to be considered by water pollution control agencies during river wastewater discharge permit analysis processes. Methodologies proposed by Kelman (1997), Hora (2001), Cardoso da Silva and Monteiro (2004), Nahon (2006), Roques (2006) and Mass Balance Equation, modified by the Brazilian Environment Ministry (2000) were analyzed and compared with respect to required dilution water flow estimates. Five scenarios were simulated, considering different effluent discharges and raw water intakes. The results showed that application of different methodologies can result in very different flow dilution value estimations. Furthermore, it was concluded that effluent and river water quality monitoring may be very useful for the selection of the more adequate methodologies and equation parameters to be employed during water permit request analysis processes. Application of methodologies that do not consider river self-purification processes usually results in overestimation of dilution flow rates downstream from the outflow discharge point. Incorporating water body quality conditions upstream from the outflow point, in turn, conditions the permit analysis to the other existing or permitted outflows. In this context evaluation of permit requests taking into account actual watercourse quality can bring the analysis process closer to reality. However, this evaluation requires further efforts in monitoring water bodies.
\end{abstract}

Keywords: Water resources. Water quality. Wastewater discharge permits. Dilution flows 


\section{INTRODUÇÃO}

O aumento populacional e a aceleração das atividades econômicas têm causado crescente utilização dos recursos hídricos e aumento das restrições relativas à qualidade das águas. Nesse contexto, um dos objetivos da Política Nacional de Recursos Hídricos (Lei no 9433/97) é assegurar às gerações atuais e futuras a disponibilidade de água, em padrões de qualidade adequados aos respectivos usos, promovendo a utilização racional e integrada dos recursos hídricos. Para isto, estabelece instrumentos a serem empregados para o gerenciamento das águas, incluindo a outorga de direito de uso de recursos hídricos (BRASIL, 1997).

Dentre os tipos de outorga previstos, a de lançamentos de efluentes constitui o principal instrumento para garantia do controle da qualidade das águas. Ela está prevista na Lei n ${ }^{\circ}$ 9433/97 (BRASIL, 1997) e foi regulamentada na Resolução no 16/01 do Conselho Nacional de Recursos Hídricos (CNRH) (BRASIL, 2001). No entanto, no Brasil, não existe consenso sobre um critério técnico para outorga de lançamento de efluentes. Além disto, diferentes estados da Federação adotam diferentes vazões de referência na adoção de critérios específicos. Dentre as adotadas por diferentes estados podem ser citadas Q7,10, Q90 e Q95. Cabe observar que muitos cursos d'água brasileiros são intermitentes, não permitindo a adoção do Q7,10.No estado do Espírito Santo, estado em que se localiza a bacia do rio Santa Maria da Vitória, na qual foi desenvolvido estudo de caso apresentado neste artigo, foi definido, em 2005, por Instrução Normativa, que o somatório das vazões outorgadas ficaria limitado a $50 \%$ da vazão de referência, Q7,10 para rios perenes e Q90 para rios intermitentes. Posteriormente, em 2009, a vazão Q90 passou a ser adotada em substituição à Q7,10.

$\mathrm{Na}$ literatura são apresentadas metodologias de estimativa de cálculo de vazões de diluição, dentre as quais podem ser citadas as desenvolvidas por Cardoso da Silva e Monteiro (2004), Hora (2001), Kelman (1997), Nahon (2006) e Roques (2006), além da estimada através da Equação de Balanço de Massa Modificada (MMA, 2000). Estas metodologias apresentam diferentes formas de cálculo para estimativa da vazão de diluição, variando os parâmetros considerados e as formas de análise dos resultados obtidos.

Neste trabalho foram estudadas e comparadas as referidas propostas metodológicas. Procurou-se analisar como cada uma considera a estimativa de vazão de diluição nas seções de lançamento e nos trechos a jusante, o processo de autodepuração e a pré-existência de lançamentos ou captações.

O estudo foi desenvolvido de forma a subsidiar escolhas, por parte de diferentes órgãos de controle de recursos hídricos, de metodologias a serem adotadas nas análises de solicitações de outorga de lançamento de efluentes. Foi desenvolvido estudo de caso, sendo realizadas simulações de diferentes cenários em uma bacia hidrográfica localizada no Espírito Santo.

Cabe observar que, apesar do caso analisado considerar uma bacia localizada em um estado da federação específico, o estudo apresenta caráter geral, objetivando subsidiar decisões a respeito de metodologias a serem empregadas em bacias localizadas, também, nos demais estados brasileiros.

\section{EQUAÇÕES DE VAZÃO DE DILUIÇÃO}

\section{Metodologia proposta por Kelman (1997)}

De acordo com Kelman (1997), um usuário que lança um efluente num curso d'água se apropria de certa quantidade de água para diluir o mesmo. A Equação (1) é sugerida pelo autor para o cálculo da vazão de diluição.

$$
\mathrm{Q}_{\mathrm{dil}_{\mathrm{x}}}=\alpha \cdot\left(\frac{\mathrm{Q}_{\mathrm{efl}} \times \mathrm{C}_{\mathrm{efl}}}{\mathrm{C}_{\max _{\mathrm{x}}}}\right)
$$

onde

$\alpha$ - coeficiente de utilização qualitativo (adimensional);

$\mathrm{Q}_{\mathrm{dil}}$ - vazão de diluição em um trecho do rio $\left(\mathrm{m}^{3} / \mathrm{s}\right)$;

$\mathrm{Q}_{\mathrm{efl}}$ - vazão do efluente lançado pelo usuário $\left(\mathrm{m}^{3} / \mathrm{s}\right)$;

$\mathrm{C}_{\mathrm{eff}}$ - concentração do poluente lançado no local $(\mathrm{mg} / \mathrm{L})$;

$\mathrm{C}_{\max _{\mathrm{x}}}$ - concentração máxima permitida do poluente no corpo d'água, conforme enquadramento $(\mathrm{mg} / \mathrm{L})$.

O coeficiente $\alpha$ indica quanto um usuário irá consumir de água para diluir seu efluente. Seu valor depende do tipo de parâmetro que está sendo lançado no curso d'água e da distância que separa a seção analisada da seção de lançamento. Se o parâmetro for conservativo, não ocorre o processo de autodepuração. No caso de parâmetros não conservativos, o poluente vai sendo degradado ao longo do curso do rio, sendo o coeficiente de utilização menor que 1 , diminuindo com a distância entre o ponto de lançamento e a seção analisada.

Segundo Kelman (1997), o valor numérico do coeficiente $\alpha$ pode ser estimado a partir do uso de modelo matemático de qualidade de água, calibrado para a bacia em estudo. Esta metodologia é adotada no estado do Espírito Santo (SALIM; ROQUES; SOUZA, 2007), no qual está localizada a bacia do rio Santa Maria da Vitória, escolhida para o desenvolvimento de estudo de caso apresentado neste artigo.

\section{Metodologia proposta por Cardoso da Silva e Monteiro (2004)}

A metodologia proposta por Cardoso da Silva e Monteiro (2004) baseia-se nos conceitos propostos por Kelman (1997) e no Sistema de Suporte à Decisão para análise técnica dos aspectos quantitativos e qualitativos dos usos da água denominado Sistema Quali-Quantitativo de Análise de Outorgas (SQAO), desenvolvido pela Secretaria de Recursos Hídricos do Ministério do Meio Ambiente (MMA, 2000).

Os autores consideram que as interferências qualitativas no corpo de água são "transformadas" em equivalentes quantitativos. A metodologia baseia-se na equação de balanço de massa para as concentrações de demanda bioquímica de oxigênio (DBO), conforme Equação (2).

$$
\mathrm{L}_{\mathrm{o}}=\frac{\mathrm{Q}_{\mathrm{r}} \cdot \mathrm{C}_{\mathrm{r}}+\mathrm{Q}_{\mathrm{efl}} \cdot \mathrm{C}_{\mathrm{efl}}}{\mathrm{Q}_{\mathrm{r}}+\mathrm{Q}_{\mathrm{efl}}}
$$


$\mathrm{Na}$ Equação (2):

$\mathrm{L}_{\mathrm{O}}$ - Concentração de DBO final (mg/L);

$\mathrm{Q}_{\mathrm{r}}$ - vazão do $\operatorname{rio}\left(\mathrm{m}^{3} / \mathrm{s}\right)$;

$\mathrm{C}_{\mathrm{r}}$ - concentração de DBO no rio $(\mathrm{mg} / \mathrm{L})$;

$\mathrm{Q}_{\text {efl }}$ - vazão do efluente lançado pelo usuário $\left(\mathrm{m}^{3} / \mathrm{s}\right)$;

$\mathrm{C}_{\mathrm{efl}}$ - concentração do poluente lançado no $\operatorname{local}(\mathrm{mg} / \mathrm{L})$.

Alterando-se alguns termos da última equação se obtém a equação de balanço qualitativo (Equação (3)), denominada de equação de diluição, proposta por Kelman (1997).

$$
\mathrm{Q}_{\text {dil }_{\mathrm{x}}}=\mathrm{Q}_{\mathrm{efl}} \cdot \frac{\mathrm{C}_{\mathrm{efl}}-\mathrm{C}_{\text {max }_{\mathrm{x}}}}{\mathrm{C}_{\text {max }_{\mathrm{x}}}-\mathrm{C}_{\text {nat }}}
$$

$\mathrm{Na}$ última equação $\mathrm{C}_{\text {nat }}$ representa a concentração natural do parâmetro no corpo receptor, imediatamente à montante da seção onde é realizado o lançamento $(\mathrm{mg} / \mathrm{L})$.

Para utilização desta metodologia, admite-se que o corpo de água se encontra na condição natural de concentração (sem interferência de outros lançamentos, apenas com matéria orgânica de folhas, galhos e fezes de animais que se encontram naturalmente na água) e não a condição atual (real, influenciada por outros lançamentos). Dessa forma, pode-se avaliar o comprometimento de qualidade associado a cada usuário, buscando-se atribuir o mesmo peso a usuários que lancem efluentes com mesmas características quantitativas e qualitativas.

O Manual Técnico de Outorgas da Superintendência de Desenvolvimento de Recursos Hídricos e Saneamento Ambiental do Paraná (SUDERHSA, 2006) utiliza a equação desenvolvida a partir da equação de balanço de massa (Equação (4)) para análises dos pleitos de outorga para lançamento de efluentes. Entretanto, considera a concentração natural $\left(\mathrm{C}_{\text {nat }}\right)$ do rio como zero, de forma a analisar o lançamento individual do usuário.

Considerando o coeficiente de utilização qualitativo $\alpha$ naEquação (3), de forma a se estimar a depuração, obtém-se a Equação (4).

$$
\mathrm{Q}_{\mathrm{dil}_{\mathrm{X}}}=\alpha \cdot\left[\mathrm{Q}_{\mathrm{efl}} \cdot \frac{\mathrm{C}_{\mathrm{efl}}-\mathrm{C}_{\max _{\mathrm{x}}}}{\mathrm{C}_{\max _{\mathrm{x}}}-\mathrm{C}_{\mathrm{nat}}}\right]
$$

Segundo Cardoso da Silva e Monteiro (2004), a Equação (3) fornecerá uma vazão de diluição que significa o quanto um usuário se apropria virtualmente da água para diluir determinado constituinte do efluente. Quando este é lançado, a vazão de diluição somada à vazão do efluente resulta na vazão de mistura, massa d'água na qual a concentração não deve ultrapassar os limites do enquadramento. Assim, a vazão de mistura do lançamento de um usuário, para determinado parâmetro, fica indisponível para outras diluições do mesmo parâmetro ao longo do curso d’água, bem como para captação (Equação (5)).

$$
\mathrm{Q}_{\text {dilindisp, } \mathrm{x}}=\mathrm{Q}_{\text {dil }_{\mathrm{x}_{\mathrm{o}}}}+\mathrm{Q}_{\mathrm{efl}}
$$

$\mathrm{Na}$ Equação (5):

$\mathrm{Q}_{\text {dil }_{\text {indisp, }} \text { - vazão de diluição que se torna indisponível para }}$ diluir outros efluentes $\left(\mathrm{m}^{3} / \mathrm{s}\right)$;

$\mathrm{Q}_{\mathrm{dil}_{\mathrm{x}_{\mathrm{o}}}}$ - vazão utilizada para diluir o efluente na seção de lan- çamento $\left(\mathrm{m}^{3} / \mathrm{s}\right)$.

É importante ressaltar que o valor de $Q_{\text {dil }_{x_{0}}}$ é obtido pela Equação (3), considerando-se os valores das variáveis na seção de lançamento do efluente.

Dependendo da natureza do parâmetro, a vazão indisponível pode sofrer decaimento natural devido ao processo de autodepuração dos corpos d'água. Para matéria orgânica o decaimento é baseado na metodologia de Streeter-Phelps. Logo, o cálculo da vazão indisponível para DBO em qualquer trecho a jusante do lançamento utilizaa Equação (6).

$$
Q_{\text {dil }} \text { indisp, } x=\frac{\left(Q_{e f l}+Q_{\text {dil }_{x_{0}}}\right) \cdot C_{\max _{x_{0}}} \cdot e^{-k_{1} \cdot t}}{C_{\max _{x}}}
$$

Na última equação:

$\mathrm{K}_{1}$ - coeficiente de desoxigenação (dia-1);

$\mathrm{t}$ - tempo de percurso(dias);

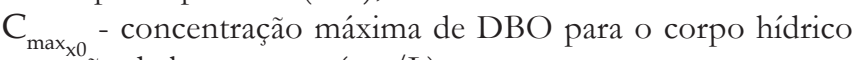
na seção de lançamento $(\mathrm{mg} / \mathrm{L})$.

A verificação de atendimento ao balanço qualitativo deve ser realizada comparando-se a vazão de diluição indisponível total $\left(Q_{\text {dil }_{\text {indisp, } x}}\right)$ de determinado parâmetro de qualidade com a vazão remanescente. Se a vazão indisponível for maior que a remanescente significa que não há água suficiente para diluir os efluentes lançados para alcance da qualidade da classe desejada.

\section{Metodologia proposta por Roques (2006)}

Para análise da diluição, Roques (2006) utilizou a Equação (4), proposta por Kelman (1997) e utilizada por Cardoso da Silva e Monteiro (2004) e MMA (2000), considerando, na análise, somente o usuário em questão, independentemente dos demais lançamentos.

A ideia da metodologia é semelhante à sugerida por MMA (2000). Assim,o usuário, ao lançar seu efluente,indisponibiliza para outros lançamentos vazão de diluição correspondente à soma da vazão de diluição do rio com a vazão do seu próprio lançamento. A vazão indisponível não é fixa ao longo do trecho, sendo seu decaimento acarretado por processos de autodepuração. Para calcular a variação da vazão indisponibilizada, Roques (2006) utilizou a ferramenta computacional QUAL2E e as variações dos valores das concentrações máximas permitidas do parâmetro analisado nos trechos a jusante (Equação (7)).

$$
\mathrm{Q}_{\text {dilindisp }, \mathrm{x}_{\text {in }}}=\alpha_{\mathrm{x}} \cdot \theta_{\mathrm{x}} \cdot \mathrm{Q}_{\text {dilindisp, } \mathrm{x} 0}
$$

\section{$\mathrm{Na}$ Equação (7):}

$a_{x}$ - coeficiente de utilização da vazão qualitativa para um parầmetro na seção x a jusante do lançamento;

$\theta_{x}$ - coeficiente de alteração da concentração máxima permitida, na seção $x$, a jusante do lançamento;

$Q_{\text {dil }_{\text {indisp }, x 0} \text { - vazão de diluição indisponível para outras diluições }}$ na seção de lançamento xo. 
Roques (2006) define as equações (8) e (9), respectivamente, para o cálculo de $a_{x}$ e $\theta_{x}$.

$$
\begin{gathered}
\alpha_{x}=\frac{C_{\text {apos }_{x}}-C_{\text {antes }_{x}}}{C_{\text {apos }_{x 0}}-C_{\text {antes }_{x 0}}} \\
\theta_{x}=\frac{C_{\max _{x}}}{C_{\max _{x 0}}}
\end{gathered}
$$

Nas duas últimas expressões:

$\mathrm{C}_{\text {apos }}$ - concentração de DBO no rio após o lançamento do efluente na seção x a jusante do lançamento, fornecida pelo modelo de simulação de qualidade de água $(\mathrm{mg} / \mathrm{L})$;

$\mathrm{C}_{\text {antes }}$-concentração de DBO no rio antes do lançamento do efluente na seção x a jusante do lançamento, fornecida pelo modelo de simulação de qualidade de água $(\mathrm{mg} / \mathrm{L})$;

$\mathrm{C}_{\text {apos } \mathrm{x} 0}$ - concentração de DBO no rio após o lançamento do efluente na seção de lançamento $\mathrm{x} 0$, fornecida pelo modelo de simulação de qualidade de água ( $\mathrm{mg} / \mathrm{L})$;

$\mathrm{C}_{\text {antes }_{\mathrm{xo}}}$ - concentração de DBO no rio antes do lançamento do efluente na seção de lançamento $\mathrm{x} 0$, fornecida pelo modelo de simulação de qualidade de água (mg/L).

Para o parâmetro DBO, a combinação das Equações

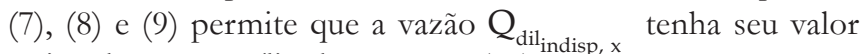
estimado com auxílio da Equação (10).

$$
Q_{\text {dilindisp, } x}=\left(\frac{C_{\text {apos }_{x}}-C_{\text {antes }_{x}}}{C_{\text {apos }_{x 0}}-C_{\text {antes }_{x 0}}}\right) \cdot\left(\frac{C_{\text {mav }_{x}}}{C_{\text {may }_{x 0}}}\right) \cdot\left(Q_{\text {dil }_{x o}}+Q_{\text {eff }}\right)
$$

Seguindo-se a metodologia, calcula-se então a vazão indisponibilizada para cada parâmetro. A cada lançamento, considera-se o maior valor de vazão,dentre aquelas associadas aos diferentes parâmetros analisados. Por fim, somam-se os valores para todos os lançamentos outorgados, obtendo-se o valor da vazão indisponível geral.

Cabe ressaltar que esta metodologia é próxima à utilizada por Cardoso da Silva e Monteiro (2004). Roques (2006) utiliza o coeficiente de decaimento qualitativo para estimar a autodepuração, enquanto que a metodologia proposta por Cardoso da Silva e Monteiro (2004) utiliza a equação de Streeter-Phelps para representar o decaimento.

\section{Metodologia proposta por Hora (2001)}

Esta metodologia considera um balanço de massa entre a carga relativa a determinado parâmetro no rio e a carga lançada por um usuário. Admite que, ao lançar um efluente, o usuário indisponibiliza qualitativamente parte da vazão do rio para jusante. Dessa forma, a metodologia procura estimar qual parte da concentração disponível do poluente o usuário estará consumindo indiretamente, expressa na forma de vazão, para diluir o seu efluente.

A concentração disponível representa a diferença entre a concentração máxima permissível $\left(\mathrm{C}_{\max _{x}}\right.$ ) a já existente no rio antes do lançamento no ponto considerado $\left(\mathrm{C}_{\text {antes }}\right)$.

Assim, por meio de um balanço entre a carga disponível para consumo, descontando-se a já existente no rio, e a carga lançada pelo usuário, obtém-se a vazão necessária para a diluição do poluente considerado (Equação (11)).

$$
\mathrm{Q}_{\mathrm{dil}_{\mathrm{x}}}=\frac{\mathrm{C}_{\mathrm{efl}} \times \mathrm{Q}_{\mathrm{efl}}}{\mathrm{C}_{\max \mathrm{x}}-\mathrm{C}_{\text {antes }}}
$$

$\mathrm{Na}$ Equação (11), representa a concentração do poluente no rio antes do lançamento $(\mathrm{mg} / \mathrm{L})$.

A cada novo pedido de outorga deverão ser recalculados balanços em todos os pontos de outorga à jusante, pois novos lançamentos alterarão a qualidade da água do rio e, consequentemente, os valores de entrada na equação relativos a outros usuários a jusante.

Para poluentes sem decaimento, a análise dos pedidos de outorga pela metodologia proposta deve ser realizada de jusante para montante, de forma a assegurar que a outorga de lançamento leve em conta todas as afluências ao curso d'água principal, evitando-se que o acúmulo do poluente ultrapasse níveis aceitáveis. Para os parâmetros não conservativos, deve ser considerado um decaimento de concentrações com o tempo, como o obtido por meio do modelo de Streeter-Phelps (Equação (12)).

$$
\mathrm{Q}_{\text {dil }_{x}}=\frac{\mathrm{C}_{\text {efl }} \times \mathrm{Q}_{\mathrm{efl}} \times \mathrm{e}^{-\left(\mathrm{K}_{1}\right) \cdot \mathrm{t}}}{\mathrm{C}_{\max \mathrm{x}}-\mathrm{C}_{\text {antes }}}
$$

\section{Metodologia proposta porNahon (2006)}

Nahon (2006) desenvolveu um sistema de apoio à análise de outorga de lançamento de efluentes para a variável DBO. Neste sistema é empregada metodologia de cálculo para vazão de diluição a partir da equação de Streeter-Phelps, considerando, além do coeficiente de desoxigenação, k1, o coeficiente de sedimentação k3. É empregado um fator de proporcionalidade (Fc) decorrente de mudanças dos limites de classe de enquadramento. Logo, a equação da concentração de mistura é obtida pela equação de balanço de massa (Equação (13)).

$$
\mathrm{Q}_{\mathrm{dil}_{\mathrm{x}}}=\left[\frac{\mathrm{Q}_{\mathrm{efl}} \cdot \mathrm{C}_{\mathrm{efl}} \cdot \mathrm{e}^{-(\mathrm{K} 1+\mathrm{k} 3) \mathrm{t}}}{\mathrm{C}_{\max _{\mathrm{x}}}}-\mathrm{Q}_{\mathrm{efl}}\right] \cdot \mathrm{F}_{\mathrm{c}}
$$

O fator de proporcionalidade é dado pelaEquação (14).

$$
\mathrm{F}_{\mathrm{c}}=\frac{\mathrm{C}_{\max _{\mathrm{x}}}}{\mathrm{C}_{\max x_{00}}}
$$

\section{Cálculo do coeficiente de decaimento qualitativo}

Kelman (1997) ressaltaque a vazão de diluição de um poluente degradável sofre decaimento ao longo do curso d'água devido à capacidade de autodepuração do corpo receptor. Esta capacidade é representada através de um coeficiente qualitativo 
$(\alpha)$ para cada seção do rio. Esse coeficiente pode ser estimado com a utilização de um modelo matemático de qualidade de água, calibrado para a bacia. O valor de $\alpha$ é menor do que a unidade e multiplica a vazão de diluição requerida em cada seção.

Rodrigues (2000) sugere a Equação (15) para cálculo do coeficiente qualitativo médio, para cada lançamento e dentro de cada trecho.

$$
\alpha=\frac{Q_{\text {dil }(x)}}{Q_{\text {dil }\left(x_{0}\right)}}
$$

Roques (2006), baseando-se na definição de Rodrigues (2000), sugere que o cálculo do coeficiente seja estimado pelaEquação (8), apresentada anteriormente. Nesta equação, a subtração da concentração do constituinte de qualidade no rio antes do lançamento $\left(\mathrm{C}_{\text {antesx }}\right)$ da concentração no rio após o lançamento $\left(\mathrm{C}_{\text {apósx }}\right.$ ) objetiva avaliar o impacto do lançamento de cada usuário individualmente, sem influência de outros, outorgados ou não (RODRIGUES, 2000; ROQUES, 2006).

\section{Aspectos relevantes a respeito das metodologias}

A metodologia estabelecida por Kelman (1997), sem a incorporação do coeficiente de decaimento, por não considerar o processo de autodepuração, pode superestimar os valores das vazões de diluição para todos os trechos do rio.

As metodologias propostas por Cardoso da Silva e Monteiro (2004) e Roques (2006) e a equação de diluição obtida através da adaptação da equação de balanço de massa com a incorporaçãodo coeficiente de decaimento qualitativo (Equação4), consideram a concentração natural de matéria orgânica do rio antes do lançamento. Esta consideração reduz a carga do efluente que pode ser lançada no rio para se atingir o enquadramento requerido, pois a quantidade de matéria orgânica natural já demanda parte da vazão do rio para sua diluição. A metodologia estabelecida por Hora (2001), por outro lado, considera a concentração de DBO anterior (real) do curso d'água, geralmente superior à $\mathrm{DBO}$ natural, podendo corresponder à concentração de $\mathrm{DBO}$ de um lançamento à montante. Além disso, os valores das vazões de diluição nos pontos de lançamento correspondentes às metodologias estabelecidas por Kelman (1997) e por Nahon (2006) - com e sem o coeficiente de decaimento - são menores, por não considerarem as concentrações de DBO pré-existentes no rio.

É relevante observar que as metodologias que utilizam o coeficiente de decaimento qualitativo apresentam decaimentos mais acentuados, quando comparados com os obtidos através de metodologias que utilizam apenas os coeficientes da equação de Streeter-Phelps.

As metodologias propostas por Hora (2001) e por Cardoso da Silva e Monteiro (2004), por só utilizarem o coeficiente k1, correspondem a menores efeitos de autodepuração ao longo dos cursos d'água, acarretando maiores valores de vazões de diluição. Por outro lado, pela metodologia estabelecida por Nahon (2006), onde se considera a sedimentação, os valores de vazões de diluição apresentam reduções mais acentuadas, quando comparadas com as correspondentes à metodologia estabelecida por Cardoso da Silva e Monteiro (2004).

As metodologias propostas Cardoso da Silva e Monteiro (2004), Nahon (2006) e Roques (2006) consideram os efeitos do lançamento a ser outorgado sobre a qualidade da água do corpo hídrico, independentemente das outras outorgas já autorizadas. Somente depois da análise dos impactos individuais, é analisado o efeito cumulativo dos outros usos no corpo hídrico. As outras metodologias não se referem aos critérios de análise do processo de outorga e apenas apresentam as equações para estimativas de vazões de diluição. A metodologia proposta por Hora (2001) considera, na análise de cada novo lançamento, a condição de concentração de DBO anterior ao lançamento no rio.

As metodologias estabelecidas por Cardoso da Silva e Monteiro (2004) e por Roques (2006) permitem que uma maior carga seja lançada no rio, pois consideram a vazão de diluição indisponível(soma da vazão de diluição na seção de análise com a vazão do efluente) para diluir a carga lançada, enquanto as outras consideram somente a vazão do rio. Cabe observar que a vazão do efluente é normalmente pequena em relação à vazão do rio. Adicionalmente, é relevante ressaltar que a metodologia definida por Roques (2006) difere da Cardoso da Silva e Monteiro (2004) por utilizar coeficiente de decaimento qualitativo para estimar a autodepuração, ao invés de utilizar a equação de Streeter-Phelps para representação do decaimento.

Conforme mostra a descrição das diversas metodologias cada uma delas apresenta particularidades. Desta forma, a escolha de uma delas para análise de solicitação de outorga dependerá, dentre outros fatores, da disponibilidade de informações a respeito de aspectos quali-quantitativos dos cursos d'água e de outros lançamentos de efluentes na bacia hidrográfica.

Metodologias que requerem informações relativas às condições reais dos cursos d'água antes do lançamento a ser outorgado apresentam como vantagem o fato da análise considerar as condições prevalentes no corpo receptor. Contudo, para suas implementações, dependem da disponibilidade de informações confiáveis a serem obtidas através de monitoramento. Monitoramento quali-quantitativo dos corpos receptores é fundamental, também, para mais precisa estimativa de parâmetros relacionados com decaimento e autodepuração necessários para aplicação da quase totalidade das metodologias.

\section{MATERIAIS E MÉTODOS}

O presente estudo baseou-se em simulações de diferentes cenários de disposição de efluentes, nos quais foram calculadas as vazões necessárias para diluição da carga de efluente lançada, com o uso das metodologias propostas, de forma a obedecer ao enquadramento do corpo hídrico, de acordo com a Resolução $\mathrm{n}^{\circ}$ 357do Conselho Nacional do Meio Ambiente, editada em 17 de março de 2005 (BRASIL, 2005).

As metodologias de vazão de diluição citadas na revisão de literatura foram estruturadas em planilhas do Microsoft Office Excel, sendo utilizado o modelo computacional QUAL-UFMG (VON SPERLING, 2007) para cálculo do coeficiente de decaimento qualitativo $(\alpha)$.Para a aplicação das referidas metodologias, 
o parâmetro de qualidade de água considerado foi a DBO.

As equações utilizadas correspondentes às metodologias apresentadas neste trabalho são referenciadas da seguinte maneira:

a) Equação da metodologia proposta por Kelman(1997) (Equação (1))sem o coeficiente de decaimento, referenciada neste trabalho como "KelmanSD";

b) Equação da metodologia de Kelman (1997) considerando o coeficiente de decaimento qualitativo, referenciada como "KelmanCD", empregada no estado do Espírito Santo, na qual está localizada a bacia do rio Santa Maria da Vitória, escolhida para o estudo de caso mostrado neste artigo;

c) Equação de diluição obtida através da adaptação da equação de Balanço de Massa, proposta por Kelman (1997), considerando o coeficiente de decaimento qualitativo(Equação (4)), referenciada como "EBMmodCD";

d) Metodologia proposta por Cardoso da Silva e Monteiro (2004) (Equação (6)), referenciada neste trabalho como "CSeM";

e) Metodologia proposta por Roques (2006) (Equação (10)), referenciada como "Roques";

f) Metodologia proposta por Hora (2001) com decaimento representado pela equação de Streeter-Phelps (Equação (11)),referenciada por "Hora";

g) Metodologia de Nahon (2006) (Equação (13)), referenciada como "Nahon".

Para as metodologias que consideram a autodepuração, esta foi calculada de três formas: (i) Utilizando-se o coeficiente de desoxigenação (k1), como propõem as metodologias CSeM e Hora; (ii) Utilizando-se os coeficientes de desoxigenação e de sedimentação (k1 e k3), como na metodologia Nahon; e (iii) Utilizando-se o coeficiente de decaimento qualitativo, calculado a partir do modelo de qualidade de água QUAL-UFMG, como nas metodologias Roques, EBMmodCD e KelmanCD.

\section{Cálculo do coeficiente de decaimento qualitativo}

Neste trabalho,quando da incorporação dos efeitos decorrentes do fenômeno de autodepuração a partir do emprego do coeficiente de decaimento qualitativo, utilizou-se a Equação (8) (ROQUES, 2006)e o modelo de qualidade de água QUAL-UFMG. Cálculo das vazões de diluição com uso do coeficiente qualitativo foi empregado para as metodologias de análise KelmanCD, EBMmodCD e Roques.

\section{Bacia piloto para aplicação das metodologias}

Foi selecionada uma sub-bacia do rio Santa Maria da Vitória, localizada no estado do Espírito Santo, para demonstração do comportamento de cada metodologia e para fundamentar a aplicação das mesmas (Figura 1). Não foi objetivo deste trabalho realizar a caracterização das condições de qualidade das águas desta bacia. Neste sentido, cabe ressaltar que os resultados são teóricos e não necessariamente representativos da realidade desta bacia hidrográfica. Contudo, procurou-se tornar os estudos de caso os mais próximos possíveis desta realidade, com utilização de informações obtidas em monitoramentos de campo realizados por Mendonça e Almeida (2005) e Souza, Salim e Cardoso da Silva (2009).

O trecho do rio Santa Maria da Vitória selecionado possui $78 \mathrm{~km}$ de extensão, compreendendo desde a nascente até a represa de Rio Bonito. Para aplicação do modelo QUAL -UFMG, dividiu-se o trecho em elementos computacionais apresentando $0,1 \mathrm{~km}$.

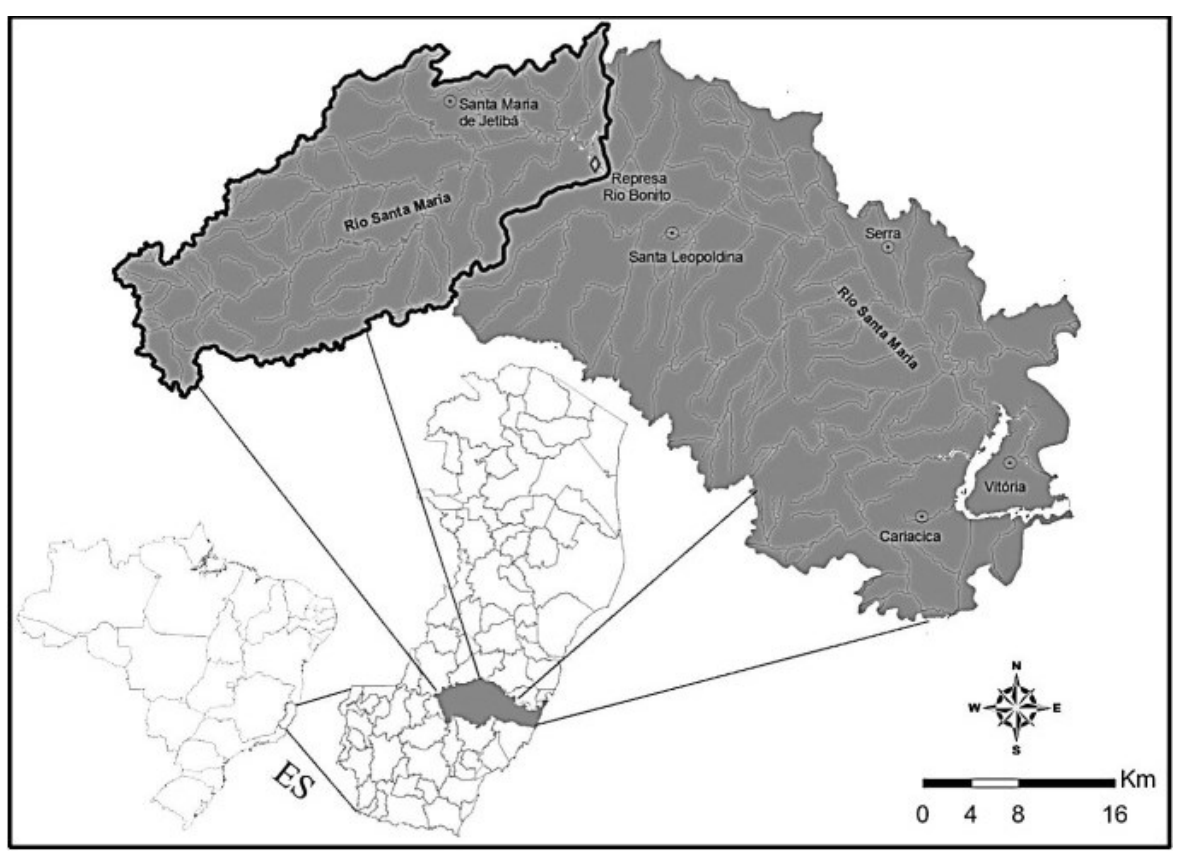

Figura 1 - Localização da sub-bacia do rio Santa Maria da Vitória 
Para todas as simulações foi considerado o período mais crítico de vazões, sendo utilizada como vazão de referência a Q7,10. A estimativa desta vazão foi baseada no trabalho de Coser (2003). A Equação (16) constitui a função regional empregada para a apropriação da referida vazão mínima de referência, estabelecida por Coser (2003) a partir do método estabelecido por Eletrobrás(1985).

$$
Q_{7,10}=10,6074 \times 10^{-3} \times A^{0,91741}
$$

O valor da área de drenagem para a cabeceira da sub -bacia foi calculado com o auxílio do ArcGis 9.3, sendo ovalor resultante136 $\mathrm{km}^{2}$. A vazão mínima estimada foi $0,96 \mathrm{~m}^{3} / \mathrm{s}$. $\mathrm{Na}$ tabela 1 são apresentados os valores de outros parâmetros utilizados na modelagem de qualidade da água.

Tabela 1 - Valores adotados dos parâmetros utilizados

\begin{tabular}{cc}
\hline Parâmetro & Valor adotado \\
\hline OD & $8 \mathrm{mg} / \mathrm{L}$ \\
\hline DBO & $1 \mathrm{mg} / \mathrm{L}^{*}$ \\
\hline Temperatura & $20^{\circ} \mathrm{C}^{* *}$ \\
\hline OD saturação & $8,11 \mathrm{mg} / \mathrm{L}$ \\
\hline $\mathrm{K}_{1}$ & $0,21 \mathrm{~d}^{-1 * *}$ \\
\hline $\mathrm{K}_{3}$ & $0,20 \mathrm{~d}^{-1 * *}$ \\
\hline
\end{tabular}

* Klein (1962) apud von Sperling (2005)

** (UFES, 1999)

*** Von Sperling (2007)

Para a metodologia estabelecida por Hora (2001), considerou-se que o valor da DBO no corpo hídrico antes do lançamento também sofre decaimento. $\mathrm{O}$ decaimento foi calculado através do modelo de Streter-Phelps, a partir do valor inicial de concentração,1 mg/L.

No estado do Espírito Santo, a quantificação das parcelas de água indisponibilizadas nos cursos de água, em virtude dos lançamentos de efluentes, fundamenta-se no conceito de vazão de diluição, proposto por Kelman (1997), e preconizado na Resolução no 016/01 da Agência Nacional de Águas (BRASIL, 2001), conforme documento intitulado "SQAO - Sistema Quali-Quantitativo de Análise de Outorgas" (MMA, 2000), elaborado pela Secretaria Nacional de Recursos Hídricos, ou seja, aquele simbolizado neste estudo com KelmanCD. Contudo, como o presente estudo objetiva auxiliar na escolha da metodologia a ser adotada na análise pelos diferentes órgãos federal e estaduais na estimativa de vazões de diluição, a aplicação desta, no estudo de caso relativo à sub-bacia do rio Santa Maria da Vitória, foi realizado em iguais condições às das demais, para permitir comparações.

\section{Fontes simuladas}

Para a simulação de cenários foram utilizadas duas cargas pontuais, descritas a seguir.

\section{Fonte pontual 1: Lançamento do efluente de uma} estação de tratamento de esgotos

Considerou-se o esgoto gerado por um município localizado na bacia e tratado por Estação de Tratamento de Esgoto (ETE), sendo lançado no curso d'água posteriormente.

A vazão de esgoto que chega à ETE foi estimada considerando a população do município, 33.663 habitantes, e um valor médio diário de consumo de água atribuído por pessoa correspondente a $145 \mathrm{~L} /$ hab.dia, multiplicado por um coeficiente de retorno (c). O valor de c, que pode variar de 60 a 100\%, foi adotado como $80 \%$. Com isso, a vazão média de esgoto que chega à ETE corresponde a $0,045 \mathrm{~m}^{3} / \mathrm{s}$. A carga per capta considerada para estações de tratamento de esgoto para o parâmetro DBO foi $54 \mathrm{~g} /$ hab.dia. A concentração de DBO foi calculada pela Equação (17) (VON SPERLING, 2005), sendo obtido o valor 467,54 mg/L. O sistema de tratamento da ETE foi considerado como um Reator UASB. Para a simulação, adotou-se eficiência de remoção de $80 \%$, obtendo-se a concentração final $93,5 \mathrm{mg} / \mathrm{L}$.

$$
\mathrm{C}_{\mathrm{e}}=\frac{\mathrm{KPC} \cdot \mathrm{Pop}}{\mathrm{Q}_{\mathrm{emed}} \cdot 86400}
$$

\section{Na Equação 17:}

KPC: carga per capta de DBO (g/hab.dia); $\mathrm{C}_{\mathrm{e}}$ - concentração de DBO no esgoto $(\mathrm{mg} / \mathrm{L})$; Pop - população do município(habitantes); $\mathrm{Q}_{\text {emed }}$ - vazão média do esgoto $\left(\mathrm{m}^{3} / \mathrm{s}\right)$.

\section{Fonte pontual 2: indústria de laticínio}

Devido à presença de atividade agroindustrial relacionada com pecuária na região, a segunda fonte de lançamento foi simulada como uma indústria de laticínio produtora de leite pasteurizado. Considerou-se que a mesma teria capacidade de produção de 300 toneladas de leite por dia e produção de efluentes de $7,5 \mathrm{~m}^{3} /$ ton (CETESB, 1990). Dessa forma estimou-se uma vazão efluente $0,025 \mathrm{~m}^{3} / \mathrm{s}$.

A concentração de $\mathrm{DBO}$ do efluente foi baseada em estimativa apresentada pela CETESB (1990),para laticínios: 290 $\mathrm{mg} / \mathrm{L}$. Adotou-se uma estação de tratamento de efluentes com eficiência de $70 \%$, estimando-se, dessa forma, uma concentração de $87 \mathrm{mg} / \mathrm{L}$ de DBO para o efluente tratado.

\section{Cenários simulados}

Foram feitas simulações de 5 cenários, com finalidade de análise do comportamento das metodologiaspara diferentes situações de lançamentos e captações. Os cenários simulados são apresentados na tabela 2 . 


\section{Tabela 2 - Cenários Simulados}

\begin{tabular}{|c|c|}
\hline $\begin{array}{c}\text { Cenário } \\
1\end{array}$ & $\begin{array}{l}\text { Fonte pontual 1, na cabeceira do rio Santa } \\
\text { Maria da Vitória. }\end{array}$ \\
\hline $\begin{array}{c}\text { Cenário } \\
2\end{array}$ & $\begin{array}{l}\text { Fonte pontual } 2 \text { no } \mathrm{Km} 9 \text {, a partir da cabeceira, } \\
\text { do rio Santa Maria da Vitória, desejando-se } \\
\text { avaliar o impacto sobre a qualidade da água } \\
\text { quando da implantação da fonte } 1 \text {, no } \mathrm{Km} 44 \\
\text { do rio. }\end{array}$ \\
\hline $\begin{array}{c}\text { Cenário } \\
3\end{array}$ & $\begin{array}{l}\text { Fonte pontual } 1 \text { no } \mathrm{km} 9 \text { do rio, a partir da } \\
\text { cabeceira, considerando a pré-existênciada fonte } \\
\text { pontual } 2 \text { no } \mathrm{Km} 44 \text { do rio. }\end{array}$ \\
\hline $\begin{array}{c}\text { Cenário } \\
4\end{array}$ & $\begin{array}{l}\text { Captação de } 0,5 \mathrm{~m}^{3} / \mathrm{s} \text { de água do rio Santa } \\
\text { Maria no } \mathrm{Km} 15 \text {, desejando-se outorgar afonte } \\
\text { pontual } 1 \text {, no } \mathrm{Km} 44 \text { do rio, a partir da } \\
\text { cabeceira. }\end{array}$ \\
\hline $\begin{array}{c}\text { Cenário } \\
5\end{array}$ & $\begin{array}{l}\text { Fonte pontual } 1 \text {, no } \mathrm{km} 9 \text {, considerando a pré- } \\
\text { existência de uma captação de } 0,5 \mathrm{~m}^{3} / \mathrm{s} \text { no } \mathrm{Km} \\
44 \text { do rio Santa Maria da Vitória. }\end{array}$ \\
\hline
\end{tabular}

\section{Análise dos lançamentos}

Conforme citado na análise das metodologias, as propostas por CSeM, Roques e Nahon consideram os efeitos do lançamento a ser outorgado sobre a qualidade da água do corpo hídrico individualmente, independentemente das outras outorgas já autorizadas. As outras metodologias apenas apresentam as equações para estimativas de vazões de diluição. A metodologia proposta por Hora considera, na análise de cada novo lançamento, a condição de concentração de DBO anterior ao lançamento no rio.

Com o intuito de padronização da análise de balanço qualitativo dos lançamentos simulados neste trabalho, considerou-se para as metodologias de KelmanSD, KelmanCD, CSeM, Roques, Nahon e EBMmodCD, primeiramente, a análise relativa aos lançamentos individuais. Posteriormente, consideraram-se, em conjunto, todos os lançamentos, através do somatório dos valores de vazão de diluição para todos os lançamentos, seção a seção (Equação (18)).

$$
\mathrm{Q}_{\mathrm{dil}_{\text {geral }}}=\sum_{\mathrm{i}=1}^{\mathrm{n}} \cdot \mathrm{Q}_{\mathrm{dil}_{1}}
$$

$\mathrm{Na}$ Equação 18:

$\mathrm{Q}_{\text {dil }}$ - - vazã no curso d'água $\left(\mathrm{m}^{3} / \mathrm{s}\right)$;

$\mathrm{Q}_{\mathrm{dil}_{1}}{ }^{-}$vazão de água necessária para diluir o lançamento do usuário i $\left(\mathrm{m}^{3} / \mathrm{s}\right)$;

$\mathrm{n}$ - número de usuários ao longo do curso d'água.

\section{RESULTADOS E DISCUSSÕES}

\section{Cenário1}

A tabela 3 e a figura 2 apresentam os resultados das simulações realizadas para o Cenário 1, obtidos pelas diferentes metodologias.

Tabela 3 - Valores de vazões de diluição, $\mathrm{em} \mathrm{m}^{3} / \mathrm{s}$, para diferentes seções do cenário 1

\begin{tabular}{ccccc}
\hline \multirow{2}{*}{ Equação } & \multicolumn{4}{c}{ Vazões de diluição $\mathbf{( m}^{\mathbf{3}} \mathbf{s} \mathbf{)}$} \\
\cline { 2 - 5 } & $\mathbf{k m 0}$ & $\mathbf{k m 2 0}$ & $\mathbf{k m 4 0}$ & $\mathbf{k m 6 0}$ \\
\hline CseM & 1,041 & 0,536 & 0,334 & 0,230 \\
\hline Hora & 1,052 & 0,490 & 0,296 & 0,201 \\
\hline EBMmodCD & 0,996 & 0,168 & 0,048 & 0,018 \\
\hline KelmanCD & 0,842 & 0,142 & 0,041 & 0,015 \\
\hline KelmanSD & 0,841 & 0,841 & 0,841 & 0,841 \\
\hline Nahon & 0,797 & 0,185 & 0,047 & 0,000 \\
\hline Roques & 1,041 & 0,175 & 0,051 & 0,019 \\
\hline
\end{tabular}

De acordo com a tabela 3, o maior valor de vazão de diluição na seção de lançamento foi obtido pela metodologia Hora $\left(1,052 \mathrm{~m}^{3} / \mathrm{s}\right)$, enquanto o menor valor $(0,797 \mathrm{~m} 3 / \mathrm{s})$ foi estimado pela metodologia Nahon. Os valores de vazões de diluição obtidos pelas metodologias CSeM, Roques e EBMmodCD foram superiores aos obtidos pelas metodologias KelmanCD, KelmanS De Nahon. Isto é justificado pelo fato das primeiras metodologias considerarem a concentração de DBO natural do curso d'água, adotada no estudo como $1 \mathrm{mg} / \mathrm{L}$, enquanto que as últimas não consideram essa variável nas estruturas das equações de diluição.

Em relação ao decaimento dos valores de vazões de diluição ocasionados pelo processo de autodepuração do rio, dentre as metodologias que consideram o decaimento de acordo com a equação de Streeter-Phelps (CSeM, Hora e Nahon), a que resultou em maiores valores de vazão de diluição e, consequentemente, menor efeito de autodepuração, foi a metodologia CSeM, seguida pela Hora e Nahon, como observado na tabela 3 e figura 2. As diferenças nos resultados obtidos pelas metodologias CSeM e Nahon são decorrentes do fato da primeira considerar apenas o coeficiente de desoxigenação $(\mathrm{k} 1)$ para representar o consumo biológico da matéria orgânica, acarretando menor grau de autodepuração, enquanto que a metodologia Nahon considera, além do coeficiente de desoxigenação (k1), o de sedimentação da DBO (k3).

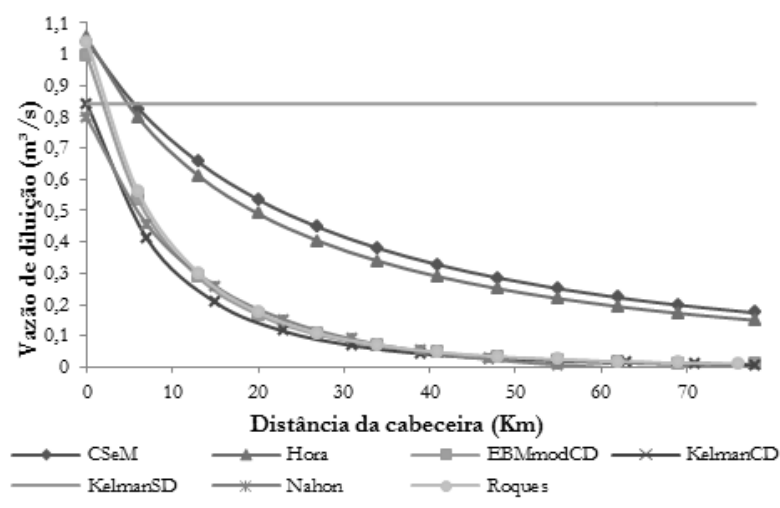

Figura 2 - Resultado das vazões de diluição obtidas na simulação do cenário 1

A metodologia Hora também considera somente o coeficiente k1. Entretanto,o decaimento é mais acentuado que 
o correspondente à metodologia CSeM, pois utiliza a concentração de DBO atual do corpo hídrico (influenciada pelo lançamento de efluentes existentes à montante). Dessa forma, leva em conta o decaimento do poluente lançado e do poluente existente antes do lançamento (no caso deste cenário $1 \mathrm{mg} / \mathrm{L}$, concentração de DBO natural assumida para a condução das simulações). Por outro lado, a concentração natural do corpo hídrico considerada para a metodologia de CSeM foi constante e igual a $1 \mathrm{mg} / \mathrm{L}$ ao longo de todo o trecho, sendo considerado apenas o decaimento do poluente lançado no rio.

Dentre as metodologias que consideram o coeficiente de decaimento qualitativo (EBMmodCD, KelmanCD e Roques), as vazões de diluição obtidas pelas metodologias Roques e EMBmodCD foram muito próximas e ligeiramente superiores às obtidas pela metodologia KelmanCD. Isso se deve ao fato das duas primeiras considerarem valores de concentrações de DBO natural do curso d'água na equação, enquanto a última não considera.

Em termos gerais, as vazões de diluição calculadas utilizando-se o coeficiente de decaimento qualitativo e as obtidas pela metodologia Nahon apresentaram reduções mais rápidas ao longo do curso do rio devido ao fato destas considerarem o coeficiente de sedimentação ( $k 3$ ), diferentemente das outras metodologias que só consideram o coeficiente de desoxigenação (k1). Entretanto, dentre estas metodologias, a metodologia Nahon apresentou menor decaimento para a vazão de diluição.

A metodologia KelmanSD resultou em valores de vazões de diluição constantes ao longo de todo curso d'água, por não considerar o processo de autodepuração. Como pode ser observado, a utilização desta metodologia superestima os valores de vazões de diluição do efluente nos trechos a jusante dos pontos de lançamento, em comparação com as demais metodologias.

\section{Cenário 2}

A tabela 4 e a figura 3 ilustram os resultados associados ao cenário 2 .

Tabela 4 - Valores de vazões de diluição, $\mathrm{em} \mathrm{m}^{3} / \mathrm{s}$, obtidas no cenário 2 , considerando apenas o lançamento a jusante, para diversas seções

\begin{tabular}{ccccc}
\hline \multirow{2}{*}{ Equação } & \multicolumn{4}{c}{ Vazões de diluição $\mathbf{( m}^{\mathbf{3}} \mathbf{s} \mathbf{~}$} \\
\cline { 2 - 5 } & $\mathbf{k m 4 4}$ & $\mathbf{k m 5 4}$ & $\mathbf{k m 6 4}$ & $\mathbf{k m 7 4}$ \\
\hline CSeM & 1,041 & 0,862 & 0,727 & 0,622 \\
\hline Hora & 1,046 & 0,832 & 0,681 & 0,569 \\
\hline EBMmodCD & 0,996 & 0,609 & 0,390 & 0,260 \\
\hline KelmanCD & 0,842 & 0,515 & 0,330 & 0,220 \\
\hline KelmanSD & 0,841 & 0,841 & 0,841 & 0,841 \\
\hline Nahon & 0,797 & 0,538 & 0,373 & 0,263 \\
\hline Roques & 1,041 & 0,636 & 0,408 & 0,272 \\
\hline
\end{tabular}

$\mathrm{Na}$ análise individual das vazões de diluição estimadas

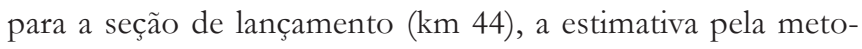
dologia Hora para este cenário foi inferior à estimativa para o cenário 1 , com redução de $1,052 \mathrm{~m}^{3} / \mathrm{s}$ para $1,046 \mathrm{~m}^{3} / \mathrm{s}$ (Tabelas 4 e 3). Esta redução se justifica pelo fato desta levar em conta a concentração de $\mathrm{DBO}$ anterior do curso d'água na seção de lançamento, e não a concentração de DBO natural. Com isso, apesar da carga lançada nos cenários 1 e 2 ser a mesma, a concentração de DBO anterior ao lançamento no curso d'água foi menor na seção do lançamento do cenário 2 do que na seção de lançamento do cenário 1 , independentemente da presença do lançamento a montante.

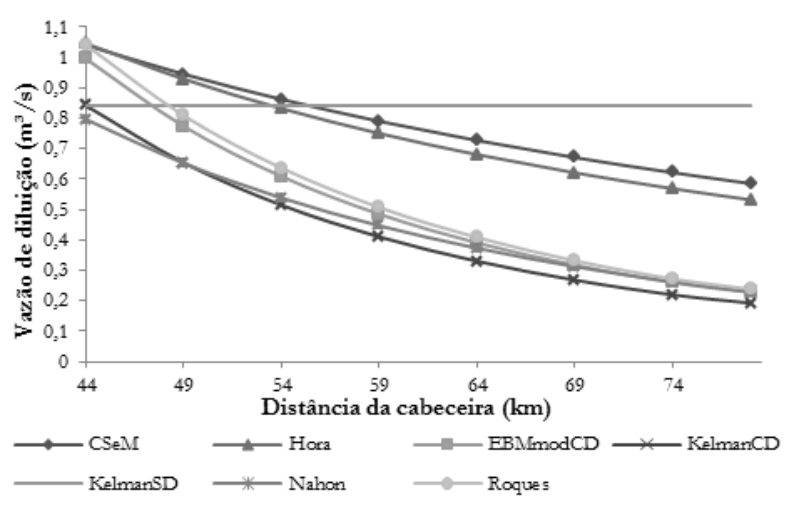

Figura 3 - Resultado da simulação do cenário 2, considerando a análise individual do lançamento a jusante

Para as outras metodologias não houve alteração nas estimativas das vazões de diluição na seção de lançamento, pois utilizam no cálculo as concentrações da DBO natural do rio, que não são influenciadas pelos lançamentos à montante. Dessa forma, as vazões de diluição para seção de lançamento não sofreram interferência devido à presença de lançamento pré-existente a montante.

Os valores estimados para vazões de diluição na seção de lançamento pela metodologia Hora são mais elevados do que os obtidos pela metodologia CSeM. Entretanto, apesar de utilizarem a mesma metodologia para estimar a autodepuração, a diminuição nos valores de vazões de diluição decorrentes do consumo de matéria orgânica ao longo do curso do rio correspondentes à metodologia Hora é maior, uma vez que esta metodologia considera tanto o decaimento da concentração do poluente do lançamento pré-existente a montante quanto o atual, enquanto que a metodologia CSeM considera o decaimento relativo apenas ao segundo lançamento.

A tabela 5 e a figura 4 ilustram os resultados relativos ao cenário 2 , considerando a existência do lançamento a montante.

Tabela 5 - Valores de vazões de diluição, $\mathrm{em} \mathrm{m}^{3} / \mathrm{s}$, para diferentes seções do cenário 2

\begin{tabular}{ccccc}
\hline \multirow{2}{*}{ Equação } & \multicolumn{4}{c}{ Vazões de diluição $\mathbf{( m}^{\mathbf{3}} \mathbf{s} \mathbf{)}$} \\
\cline { 2 - 5 } & $\mathbf{k m} \mathbf{9}$ & $\mathbf{k m 4 3}$ & $\mathbf{k m 4 4}$ & $\mathbf{k m 7 0}$ \\
\hline CSeM & 0,538 & 0,227 & 1,263 & 0,732 \\
\hline Hora & 0,508 & 0,195 & 1,046 & 0,610 \\
\hline EBMmodCD & 0,513 & 0,050 & 1,044 & 0,319 \\
\hline KelmanCD & 0,435 & 0,043 & 0,882 & 0,270 \\
\hline KelmanSD & 0,435 & 0,435 & 1,276 & 1,276 \\
\hline Nahon & 0,410 & 0,056 & 0,849 & 0,309 \\
\hline Roques & 0,538 & 0,053 & 1,091 & 0,334 \\
\hline
\end{tabular}


Ao considerar o lançamento à montante, o somatório das vazões de diluição para o trecho a jusante do lançamento, obtido através da metodologia KelmanSD, apresentou maior valor de vazão de diluição, $1,276 \mathrm{~m}^{3} / \mathrm{s}$ (Tabela 5), mostrando a importância da consideração da autodepuração, no sentido de não subestimar o potencial de diluição do rio.

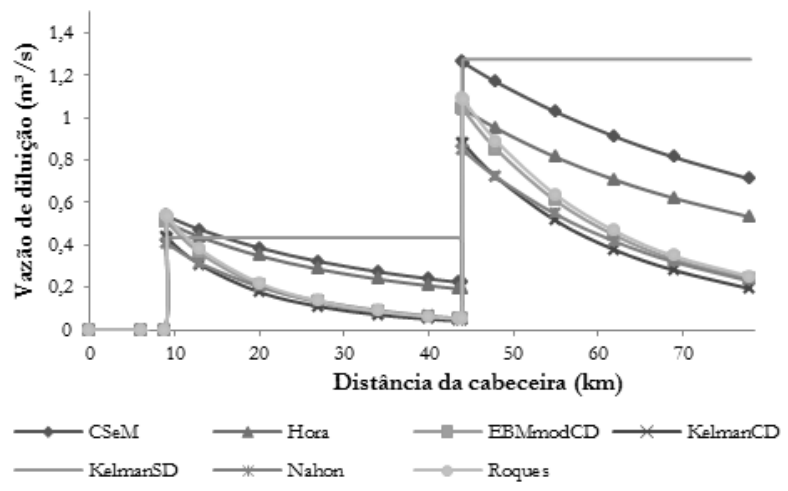

Figura 4 - Resultado da simulação do cenário 2, considerando os somatórios das vazões de diluição nas seções

Observando apenas as metodologias que consideram a autodepuração, CSeM estimou maiores valores de vazões de diluição na seção de lançamento $\left(1,263 \mathrm{~m}^{3} / \mathrm{s}\right)$. Isto se deve ao fato desta metodologia só utilizar o coeficiente de desoxigenação para representar o decaimento da concentração de DBO, que fez com que a depuração da matéria orgânica até a seção do segundo lançamento fosse menor do que as estimadas pelas outras metodologias.

As metodologias Nahon e KelmanCD apresentaram os menores valores de vazões de diluição na seção do segundo lançamento. Os valores referentes ao lançamento pré-existente, na seção imediatamente à montante do novo lançamento, estimadas pelas metodologias Roques e EBMmodCD foram 0,053 e $0,050 \mathrm{~m}^{3} / \mathrm{s}$, respectivamente, superiores apenas aos valores obtidos pela metodologia KelmanCD $\left(0,043 \mathrm{~m}^{3} / \mathrm{s}\right)$. Contudo, as estimativas para as mesmas metodologias na seção do novo lançamento alcançaram valores superiores a $1 \mathrm{~m}^{3} / \mathrm{s}$, com aumentos superiores aos obtidos pelas metodologias Nahon e KelmanCD. Isto pode ser explicado pelo fato das metodologias Roques e EBMmodCD considerarem, para o novo lançamento, a concentração natural de DBO do rio, enquanto as outras metodologias não o fazem.

\section{Cenário 3}

A tabela 6 e a figura 5 ilustram os resultadosdo cenário 3. Como as metodologias CSeM, KelmanCD, KelmanSD, EBMmodCD, Nahon e Roques analisam cada lançamento individualmente, as mesmas não consideraram o aumento da vazão de diluição devido à presença de lançamento pré-existente

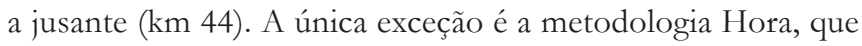
considera a concentração de DBO do rio antes do lançamento, o que gerou aumento da vazão de diluição no $\mathrm{km} 44$. As outras metodologias tiveram comportamento similar à simulação de um único lançamento, como observado anteriormente.
Tabela 6 - Valores de vazões de diluição, $\mathrm{em} \mathrm{m}^{3} / \mathrm{s}$, obtidas para o cenário 3 , considerando somente o lançamento a montante

\begin{tabular}{ccccc}
\hline \multirow{2}{*}{ Equação } & \multicolumn{4}{c}{ Vazões de diluição $\mathbf{( m}^{\mathbf{3}} \mathbf{s} \mathbf{)}$} \\
\cline { 2 - 5 } & $\mathbf{k m ~ 9}$ & $\mathbf{k m ~ 4 3}$ & $\mathbf{k m} \mathbf{4 4}$ & $\mathbf{k m ~ 7 0}$ \\
\hline CSeM & 1,041 & 0,439 & 0,430 & 0,273 \\
\hline Hora & 0,982 & 0,378 & 0,640 & 0,347 \\
\hline EBMmodCD & 0,996 & 0,100 & 0,095 & 0,029 \\
\hline KelmanCD & 0,842 & 0,085 & 0,080 & 0,025 \\
\hline KelmanSD & 0,841 & 0,841 & 0,841 & 0,841 \\
\hline Nahon & 0,797 & 0,111 & 0,105 & 0,017 \\
\hline Roques & 1,041 & 0,105 & 0,099 & 0,030 \\
\hline
\end{tabular}

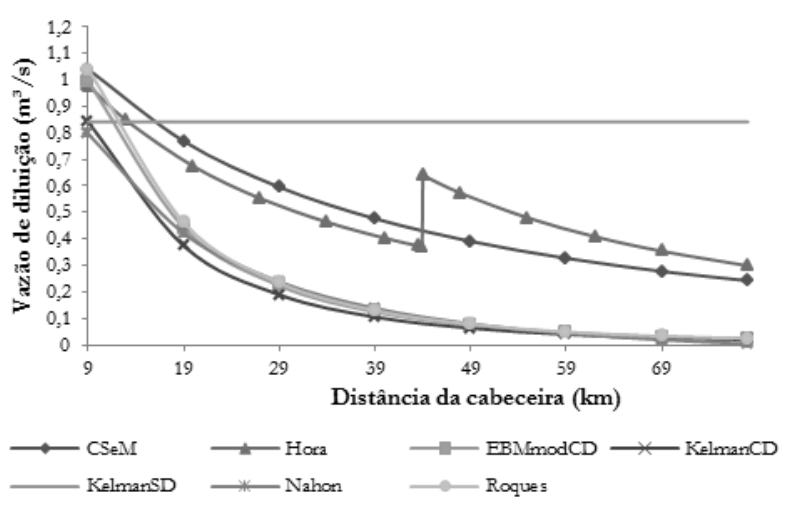

Figura 5 - Resultado da simulação do cenário 3, considerando a análise individual do lançamento a montante

A tabela 7 e a figura 6 demonstram resultados do somatório das vazões de diluição em diferentes seções do rio, quando considerados os dois diferentes lançamentos que deram forma ao cenário 3. Assim como no cenário 2, a metodologia KelmanSD apresentou os maiores valores de vazão de diluição. Dentre as metodologias que consideram a autodepuração, osvalores estimados pela metodologia de CSeM foram mais elevados, por esta só considerar o coeficiente k1.

Tabela 7 - Valores de vazões de diluição, $\mathrm{em} \mathrm{m}^{3} / \mathrm{s}$, para diferentes seções do cenário 3

\begin{tabular}{ccccc}
\hline \multirow{2}{*}{ Equação } & \multicolumn{4}{c}{ Vazões de diluição $\mathbf{( m}^{\mathbf{3}} \mathbf{s} \mathbf{~}$} \\
\cline { 2 - 5 } & $\mathbf{k m} \mathbf{~}$ & $\mathbf{k m 4 3}$ & $\mathbf{k m} \mathbf{4 4}$ & $\mathbf{k m 7 0}$ \\
\hline CSeM & 1,041 & 0,439 & 0,968 & 0,615 \\
\hline Hora & 0,982 & 0,378 & 0,640 & 0,347 \\
\hline EBMmodCD & 0,996 & 0,100 & 0,608 & 0,185 \\
\hline KelmanCD & 0,842 & 0,085 & 0,515 & 0,157 \\
\hline KelmanSD & 0,841 & 0,841 & 1,277 & 1,276 \\
\hline Nahon & 0,797 & 0,111 & 0,495 & 0,151 \\
\hline Roques & 1,041 & 0,105 & 0,637 & 0,194 \\
\hline
\end{tabular}

Para as demais metodologias (EBMmodCD, KelmanCD, Nahon e Roques) o comportamento dos resultados foi similar ao correspondente Cenário 2. 


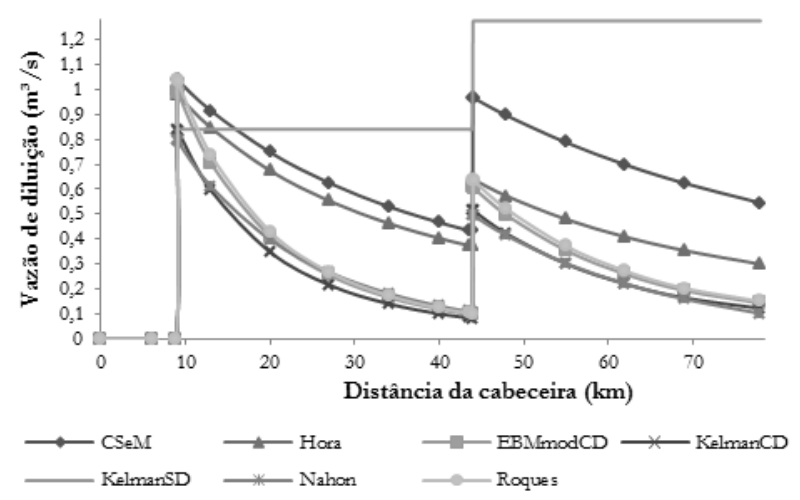

Figura 6 - Resultado da simulação para o cenário 3, considerando os somatórios das vazões de diluição nas seções

Apesar de apresentarem valores próximos nas seções imediatamente à montante do segundo lançamento, as metodologias Roques e EBMmodCD obtiveram valores mais elevados de vazão de diluição na seção de lançamento, quando comparada com as metodologias Nahon e KelmanCD. Este fato é devido à consideração da Concentração Natural $\left(\mathrm{C}_{\text {nat }}\right)$ do rio nas equações que dão forma a estes métodos.

\section{Cenário 4}

A tabela 8 e a figura 7 mostram os resultados das simulações para o Cenário 4. Considerando-se que, neste cenário, não existe lançamento adicional de matéria orgânica à montante do lançamento, foi realizada apenas a análise associada ao lançamento no quilômetro 44.

Tabela 8 - Valores de vazões de diluição, $\mathrm{em} \mathrm{m}^{3} / \mathrm{s}$, obtidas para diferentes seções do cenário 4

\begin{tabular}{ccccc}
\hline \multirow{2}{*}{ Equação } & \multicolumn{4}{c}{ Vazões de diluição $\mathbf{( m}^{\mathbf{3}} \mathbf{\text { s) }}$} \\
\cline { 2 - 5 } & $\mathbf{k m 4 4}$ & $\mathbf{k m 5 4}$ & $\mathbf{k m 6 4}$ & $\mathbf{k m 7 4}$ \\
\hline CSeM & 1,041 & 0,835 & 0,686 & 0,547 \\
\hline Hora & 0,885 & 0,703 & 0,573 & 0,477 \\
\hline EBMmodCD & 0,996 & 0,555 & 0,331 & 0,208 \\
\hline KelmanCD & 0,842 & 0,469 & 0,280 & 0,176 \\
\hline KelmanSD & 0,841 & 0,841 & 0,841 & 0,841 \\
\hline Nahon & 0,797 & 0,502 & 0,328 & 0,219 \\
\hline Roques & 1.041 & 0,580 & 0,346 & 0,217 \\
\hline
\end{tabular}

Com exceção da metodologia Hora, nenhuma outra apresentou alteração no valor da vazão de diluição na seção de lançamento devido à presença da captação a montante. Isso se deve ao fato das demais metodologias não considerarem diretamente nas equações a vazão do rio. Entretanto, a diminuição da vazão devido à captação alterou o processo de autodepuração pelo fato de ter acarretado diminuição nas velocidades do curso d'água e,consequentemente, aumentado o tempo de percurso. Isto ocasionou menores valores de vazões de diluição ao longo do curso d'água, para todas as metodologias, quando comparados com os valoresapresentados na tabela 4 , correspondendo a maior depuração no curso d'água.

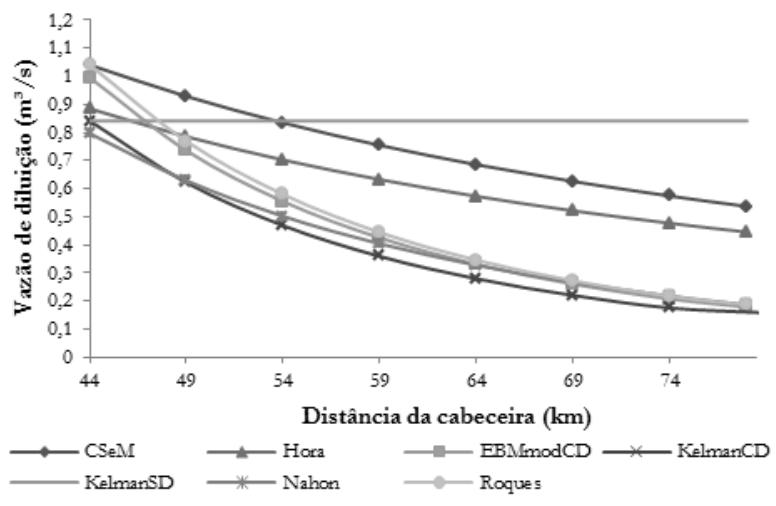

Figura 7 - Resultado das vazões de diluição obtido na simulação do cenário 4

A metodologia Hora apresentou redução no valor da vazão de diluição na seção de lançamento, pois o valor da concentração de DBO na seção imediatamente anterior à seção de lançamento era menor, devido à maior depuração ocasionada pela captação que reduziu o tempo de percurso da água no rio.

\section{Cenário 5}

A tabela 9 e a figura 8 ilustram os resultados das simulações relativos ao cenário 5. As metodologias apresentaram diminuições maiores nos valores das vazões de diluição ao longo do percurso do rio, a partir da seção de captação (km 44). Esta redução foi decorrente do tempo de percurso utilizado para calcular o decaimento, uma vez que o mesmo é função da vazão do curso d'água e da velocidade do rio. Os valores das vazões de diluição não se alteraram na seção de lançamento. Entretanto, a metodologia Hora apresentou menor valor de vazão de diluição na seção de lançamento, quando comparada com a vazão indicada na tabela 3 , pelo fato desta metodologia considerar a autodepuração da matéria orgânica presente anteriormente no curso d'água (no caso, a concentração natural).

Tabela 9 - Valores de vazões de diluição, $\mathrm{em} \mathrm{m}^{3} / \mathrm{s}$, obtidas com o lançamento para diferentes seções do cenário 5

\begin{tabular}{ccccc}
\hline \multirow{2}{*}{ Equação } & \multicolumn{4}{c}{ Vazões de diluição $\left(\mathbf{m}^{\mathbf{3}} \mathbf{s} \mathbf{)}\right.$} \\
\cline { 2 - 5 } & $\mathbf{k m 9}$ & $\mathbf{k m 4 3}$ & $\mathbf{k m 4 4}$ & $\mathbf{k m 7 0}$ \\
\hline CSeM & 1,041 & 0,439 & 0,430 & 0,254 \\
\hline Hora & 0,982 & 0,378 & 0,370 & 0,213 \\
\hline EBMmodCD & 0,996 & 0,100 & 0,095 & 0,029 \\
\hline KelmanCD & 0,842 & 0,085 & 0,080 & 0,024 \\
\hline KelmanSD & 0,841 & 0,841 & 0,841 & 0,841 \\
\hline Nahon & 0,797 & 0,111 & 0,105 & 0,009 \\
\hline Roques & 1,041 & 0,105 & 0,099 & 0,030 \\
\hline
\end{tabular}

Comparando-se os valores de vazões de diluição na seção de lançamento deste cenário com os valores estimados no cenário 4, observa-se que os resultados obtidos pela metodologia Hora no cenário 5 são menores que os do cenário 4 nas seções de lançamento, apesar da carga lançada ser a mesma(Tabela 8 e Figura 7). Isto se deve ao fato do valor da concentração de DBO na seção imediatamente anterior à de lançamento ter menor 
valor no cenário 5. Este menor valor é decorrente do local de lançamento que é mais próximo da cabeceira do rio do que a

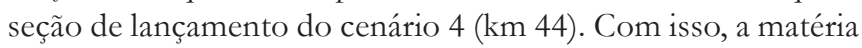
orgânica do rio, no cenário 4 , é mais consumida.

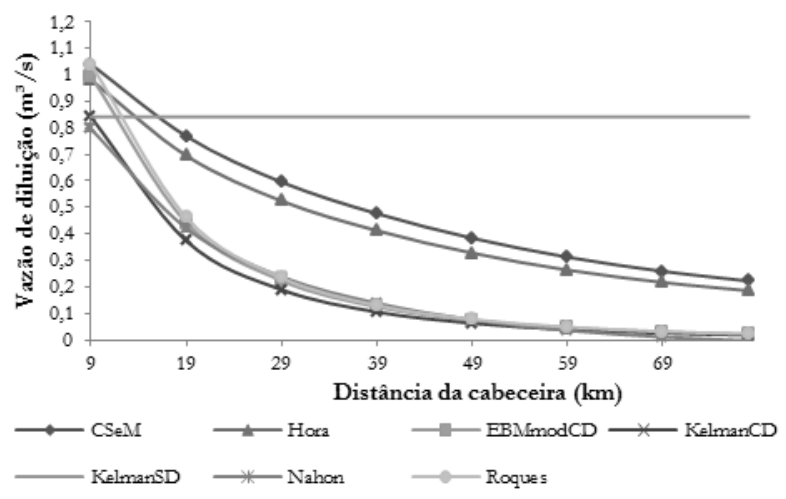

Figura 8 - Resultado das vazões de diluição obtido na simulação do cenário 5

\section{SÍNTESE DOS RESULTADOS}

Os resultados indicam que, para os cenários simulados, com os parâmetros adotados, para os trechos do rio Santa Maria da Vitória considerados, as metodologias para as quais seriam requeridas maiores vazões de diluição dos efluentes simulados seriam os simbolizados por KelmanSD, CSeM e Hora. Por outro lado, a metodologia KelmanCD resultou nas menores vazões. Excluindo-se, a metodologia KelmanSD, que resultou, como esperado, nas maiores vazões, constantes, para a quase totalidade dos cenários os valores de vazões diluição estimadas pelos diferentes métodos formaram dois grupos. O primeiro grupo, formado pelos resultados da aplicação dos métodos CSeM e Hora, enquanto que o segundo, apresentando os menores valores, seria formado pelos resultados correspondentes aos demais. Mais baixos valores de vazões de diluição estimados pelas metodologias KelmanCD e Nahon eram esperados, pelo fato destas não considerarem as concentrações de DBO pré-existentes no corpo receptor, neste caso o rio Santa Maria da Vitória. A metodologia adotada no estado do Espírito Santo para análise de outorga de diluição de efluentes,KelmanCD, segundo Salim, Roques e Souza (2007), foi a que resultou em menores valores. Cabe observar que os resultados obtidos são específicos para as condições simuladas para trechos do rio Santa Maria da Vitória e foram influenciados pelos parâmetros adotados.

\section{CONCLUSÕES E RECOMENDAÇÕES}

Os resultados das estimativas de vazões de diluição obtidos para diferentes cenários de lançamentos de efluentes no rio Santa Maria da Vitória demonstram que as diferentes metodologias apresentadas na literatura para estimativas de vazões de diluição de efluentes podem resultar em valores muito diversos. Estes resultados refletem, em diversos aspectos, as peculiaridades das diversas metodologias.

A não consideração do processo de autodepuração, como ocorre na aplicação da metodologia KelmanSD, resulta geralmente em superestimação de valores de vazões de diluição a jusante dos pontos de lançamento previstos, comparativamente aos estimados por meio das demais metodologias. Essa superestimativa pode impedir a aprovação de solicitações de outorga de lançamento posteriores. Entretanto, a metodologia KelmanSD permitiria estimativa de vazões de diluição associadas aparâmetros conservativos de qualidade de água, não sujeitos a depuração.

A consideração da concentração de DBO no corpo hídrico a montante do lançamento $\left(\mathrm{C}_{\text {antes }}\right)$, como sugere Hora, ao invés da análise individual de cada lançamento, faz com que a outorga fique condicionada aos outros lançamentos já existentes anteriormente no rio, outorgados ou não. Além disso, a utilização deste parâmetro exige que se faça um monitoramento constante da qualidade das águas do rio ao longo do tempo, podendo gerar custos elevados para os órgãos ambientais.Por outro lado, a análise do lançamento individual de cada usuário permite a avaliação de quanto da vazão do rio este comprometerá, de forma independente, facilitando, futuramente, a implantação do sistema de cobrança, pelo qual o usuário pagará apenas pela carga que ele realmente lança.Entretanto, a análise dos pleitos de outorga que considere a real qualidade do curso d'água pode tornar o processo de análise mais próximo da realidade.

Captações pré-existentes a montante ou jusante, pelo fato de influírem nas vazões, velocidades e tempos de percurso nos trechos do curso d'água, podem exercer grande influência sobre o processo de autodepuração e, consequentemente, nas estimativas de vazões de diluição.

Em relação à estimativa da autodepuração do rio, a utilização do coeficiente de decaimento qualitativo $(\alpha)$ pode ser mais realista ao processo de autodepuração do que a simples utilização direta dos coeficientes de desoxigenação e sedimentação (k1 e k3), uma vez que através de modelos de qualidade de água, como o QUAL-UFMG, é possível considerar maior quantidade de parâmetros e coeficientes, caso estejam disponíveis informações a respeito da qualidade dos cursos d'água. Por outro lado, caso não existam, a utilização apenas do coeficiente de desoxigenação $(\mathrm{k} 1)$ representa alternativa para estimativada autodepuração. Neste sentido, é de grande importância a boa calibração dos coeficientes, tanto para utilização do modelo de qualidade d'água quanto da simples equação de Streeter-Phelps, uma vez que valores inadequados podem sub ou superestimar os valores de vazões de diluição.

Este trabalho mostra, através de simulações, quanto os valores de vazões de diluição podem variar, em função das metodologias e, desta forma, fornece subsídios para tomadas de decisão por órgãos gestores de recursos hídricos. Cabe, entretanto,a estes órgãos avaliar qual dessas metodologias é mais adequada para aplicação, dependendo das características dos cursos d'água nos quais os lançamentos ocorrerão, da disponibilidade de informações a respeito do rio em questão, dos recursos disponíveis para monitoramento de vazões e qualidade de água e do rigor a ser adotado nas análises de solicitações de outorga para lançamento. A aplicação da metodologia KelmanCD, adotada nas análises de solicitações de outorga no estado 
do Espírito Santo, onde a bacia do rio Santa Maria da Vitória se localiza, considerando os parâmetros adotados nos diversos cenários, conduziria a estimativas de vazões de diluição menores do que as obtidas através das demais metodologias.

\section{REFERÊNCIAS}

BRASIL. Lei Federal n. ${ }^{\circ}$ 9.433, de 8 de janeiro de 1997. Diário Oficial [da] República Federativa do Brasil, Brasília, 8 jan. 1997.

BRASIL. Resolução n. 357 do Conselho Nacional do Meio Ambiente, de 17 de março de 2005. Diário Oficial [da] República Federativa do Brasil, Brasília, 19 mar. 2005.

BRASIL. Resolução n. ${ }^{\circ} 16$ do Conselho Nacional de Recursos Hídricos (CNRH), de 8 de maio de 2001. Diário Oficial [da] República Federativa do Brasil, Brasília, 8 maio 2001.

BROWN , L. C.; BARNWEEL JUNIOR, T. O. The enhanced stream water quality models QUAL2E and QUAL2E-UNCAS: documentation and user manual. Georgia: EPA, 1987.

CARDOSO da Silva, L. M.; MONTEIRO, R. A. Outorga de Direito de Uso de Recursos Hídricos: uma das possíveis abordagens. In: MACHADO, C. J. S. (Org.). Gestão de Águas Doces. Rio de Janeiro: Interciência, 2004. . cap. 5, p. 135-178.

CETESB - Companhia de Tecnologia de Saneamento Ambiental. Nota Técnica sobre Tecnologia de Controle: indústria de laticínios. NT-17. São Paulo: CETESB, 1990.

COSER, M. C. Regionalização de vazões Q7,10 no Estado do Espírito Santo. 2003. 160 f. Dissertação (Mestrado em Engenharia Ambiental) - Programa de Pós-Graduação em Engenharia Ambiental, Universidade Federal do Espírito Santo, Vitória, 2003.

ELETROBRÁS. Centrais Elétricas Brasileiras S.A. Metodologia para regionalização de vazões. Rio de Janeiro: ELETROBRÁS, 1985.

HORA, A. F. Metodologia para outorga do uso de recursos hídricos com ênfase no caso de aproveitamentos hidrelétricos. 2001. 256 f. Tese (Doutorado em Ciências em Engenharia de produção) - Universidade Federal do Rio de Janeiro, Rio de Janeiro, 2001.

KELMAN, J. Gerenciamento de recursos hídricos: Parte I - outorga. In: SIMPÓSIO BRASILEIRO DE RECURSOS HÍDRICOS, 12., 1997, Vitória. Anais... Rio de Janeiro: ABRH, 1997. p. 123-128.

MENDONÇA, A. S. F.; ALMEIDA, M. M.. Definição de alternativas de eficiências de tratamento de efluentes para manutenção de padrões ambientais. In: SIMPÓSIO BRASILEIRO DE RECURSOS HÍDRICOS, 16., 2005, João Pessoa. Anais... João Pessoa: ABRH, 2005. p. 501-510.
MMA - Ministério do Meio Ambiente. Secretaria de Recursos Hídricos (SRH/MMA). SISAGUA - Sistema de Apoio ao Gerenciamento de Usuários de Água. Brasília: Ministério do Meio Ambiente, 2000.

NAHON, I. M. Sistema de apoio à análise de outorga de lançamento de efluentes para a variável Demanda Bioquímica de Oxigênio: estudo de caso da Bacia do Alto Iguaçu. 2006. 147 f. Dissertação (Mestrado em Engenharia de Recursos Hídricos e Ambiental). Universidade Federal do Paraná, Curitiba, 2006.

RODRIGUES, R. B. Metodologia de apoio à concessão de outorga para diluição de efluentes e cobrança pelo uso da água - o modelo RM1. 2000. 140 f. Dissertação (Mestrado em Engenharia Civil) - Escola Politécnica da Universidade de São Paulo, São Paulo, 2000.

ROQUES, T. V. P. Aplicação de modelos computacionais na análise de outorga para diluição de efluentes em corpos de águafontes pontuais e difusas. 2006. 201 f. Dissertação (Mestrado em Engenharia Ambiental) - Universidade Federal do Espírito Santo, Vitória, 2006.

SALIM, F. C. P.; ROQUES, T. V. P.; SOUZA W. G. Definição de critérios técnicos de análise de outorga para diluição de efluentes em cursos de água: o caso do estado do Espírito Santo. In: SIMPÓSIO BRASILEIRO DE RECURSOS HÍDRICOS, 17., 2007, São Paulo. Anais... São Pulo: ABRH, 2007. CD-ROM.

SOUZA, W. G.; SALIM, F. P. C.; CARDOSO DA SILVA, L. M. Aplicação de Metas progressivas de melhoria de qualidade de água no processo de outorga para diluição de efluentes. In: SIMPÓSIO BRASILEIRO DE RECURSOS HÍDRICOS, 18. 2009, Campo Grande. Anais... Rio de Janeiro: ABRH, 2009. CD-ROM.

SUDERHSA - Superintendência de Desenvolvimento de Recursos Hídricos e Saneamento Ambiental . Manual técnico de Outorgas. Paraná: Superintendência de Desenvolvimento de Recursos Hídricos e Saneamento Ambiental, 2006.

UFES - UNIVERSIDADE FEDERAL DO ESPÍRITO SANTO. Grupo de Estudo e Ações em Recursos Hídricos (UFES/ GEARH). Inter-relações entre ambientes e qualidade das águas das bacias dos rios Jucu e Santa Maria da Vitória. Vitória: UFES, 1999.

VON SPERLING, M. Estudos e modelagem da qualidade da água de rios: princípios do tratamento biológico de águas residuárias. Belo Horizonte: DESA/UFMG, 2007.

VON SPERLING, M. Introdução à qualidade das águas e ao tratamento de esgotos. 3 ed. Belo Horizonte: DESA/UFMG, 2005. 